\title{
Occasional piece
}

\section{If jogging is a joke, who should have the last laugh?}

It was the end of my sabbatical in Canada, and I was strolling around Stanley Park, one of the many jewels of Vancouver British Columbia. I was just finishing a four month trip in Australia and Canada studying educational methods used to teach general practitioners. OK I'll come clean-I was having an "extended holiday with a purpose". On this beautiful autumnal Sunday, the air was crisp and, as the sun sparkled on Burrard Inlet, the colours of the spruce, maple, and arbutus painted the lower slopes of the snow clad peaks across the bay. "No wonder this is one of the most popular places to live in our world" I thought.

Despite this idyll most of the people I saw that day looked ill at ease, in pain even. Why? I hear you ask. The answer is obvious: they were jogging! Why is an activity that is so blatantly uncomfortable so universally popular? At least it is good for them I thought.

Weeks later I was idly sharing these observations with a friend. $\mathrm{He}$ asked casually for another example of a bodily system that functions better when systematically stressed over a long period of time. I struggled for an answer. I was left wondering if jogging was a joke-at least in health terms anyway.

The World Health Organisation ${ }^{1}$ made the observation that jogging reduces health care costs, work absenteeism, and even increases productivity. So it's good for your boss and the government at any rate. How reliable are these statements? As in many WHO documents, this is not specifically discussed. Certainly, being very active seems to alter your lipid profile favourably (raised HDL, lower VLDL and triglyceride levels, possibly lower LDL levels). ${ }^{23}$ International athletes, however, have the same life expectancy as the rest of us, so what level of exercise are we talking about? The national runners health study ${ }^{4}$ suggests that, to achieve significant cardiovascular benefits, the jogger needs regularly to run in excess of $64 \mathrm{~km}$ a week or 7 miles a day. This means that the joggers in Stanley Park would have to do their run daily. Perhaps they do. A primary care study in the United Kingdom ${ }^{5}$ showed significant reductions in the death rate with a lifelong exercise programme. However, this programme had to include vigorous exercise starting in the 15-25 year age range, and the study numbers were small. Farrell et $a l^{6}$ showed that jogging, in the absence of other risk factors (smoking, hypertension, abnormal lipid profile), had the potential to achieve a $30 \%$ reduction in cardiovascular disease risk. However, if the jogger smokes, the level of exercise required to lower the risk rises dramatically, and if hypertension is present, then the gain is not significant at any level of exercise.

I keep telling my marathon running colleague that I have his NHS wheelchair on order, and the studies suggest that I may not be wrong. Knee pain has been shown to correlate with total "jogging years" and hours a week. ${ }^{7}$ Lifelong jogging increases the chances of making friends with your local orthopaedic surgeon, ${ }^{78}$ and that is without the increased risk of stress fractures and minor orthopaedic complaints. The literature is full of the hazards of urban jogging; if the traffic doesn't get you, the pollution might. There is a possible link between urban ozone levels and lung inflammation. ${ }^{14}$

Unfortunately, the evidence that joggers are at least strengthening their bones is also equivocal. Although bone density at the hip may increase, no reduction in osteoporotic related fractures has been shown. ${ }^{10}$ If all that's not enough, a Swedish study ${ }^{11}$ has shown an increased risk of arrhythmia in elderly male joggers (average age 73.2 years). The potential for sudden death during jogging is well documented and probably represents a cardiovascular event. There has also been some suggestion that too much jogging can actually impair the immune system and increase the incidence of minor infection, although this seems to be speculative. Some runners report an improvement in visual acuity during exercise (so perhaps these Canadians can see their mountains more clearly than I), but this seems to be a subjective experience (they only think they can see them more clearly), and, except for perhaps a small reduction in intraocular pressure, no effects on the eye are apparent. ${ }^{12}{ }^{13}$ There is a report of some improvement in the symptoms of diverticular disease after jogging, ${ }^{14}$ although I doubt many joggers have this in mind as they don their trainers. And then there is joggers nipple, but we won't dwell on that!

Now you may have formed the impression that I don't jog, and you would be mostly right. I'm certainly not a habitual jogger, although I do dabble occasionally. I still feel that man is essentially a Stone Age animal living in the modern world. For the life of me, I can't imagine Stone Age man jogging. Running like hell to escape a snack-seeking carnivore: yes. Strolling along collecting berries: yes. Jogging: I just can't see it. It seems so unnatural.

So how do I feel about my jogging compatriots? I still have this deeply British admiration for the "no pain, no gain" philosophy. Mostly I hope the joggers do enjoy running (but I do wish they'd smile). I will continue to extol the virtues of the healthy lifestyle to my patients, and I'm sure exercise is in there somewhere. However, I'm not convinced that the joggers will need my services any less than my "normal" patients-whoever they are!

Now-anyone fancy a nice walk?

P I MIDDLETON

The Caxton Surgery, Oswestry, Shropshire

1 Briazgounov IP. The role of physical activity in the prevention and treatment of non-communicable disease. World Health Stat Q 1998;41:242-50.

2 Suter E, Marti B, Gutzwiller F. Jogging or walking: comparison of health effects. Ann Epidemiol 1994;4:375-81.

3 Suter A, Marti B, Tschopp A, et al. Effects of self-monitored jogging on physical fitness, blood pressure and serum lipids in sedentary middle-aged men. Int $\mathcal{F}$ Sports Med 1990;11:425-32.

4 Williams PT. Relationship of distance run per week to coronary heart disease risk factors in 8283 runners. The National Runners Health Study. disease risk factors in 8283 runners.

5 Shinton R, Sagar G. Lifelong exercise and stroke. BMF 1993;307:231-4.

5 Shinton R, Sagar G. Lifelong exercise and stroke. BMF 1993;307:231-4.
6 Farrell SW, Kampert JB, Kohl III WW. Influences of cardiorespiratory

fitness levels and other predictors on cardiovascular disease mortality in men. Med Sci Sport Exerc 1998;30:899-905.
men 
7 Haln T, Foldspang A. Prevalent knee pain and sport. Scand f Soc Med 1998; 26:44-52.

8 Nitzsche E, Leonhardt R. Jogging: stress induced damage of the musculoskeletal system. Sportverletz Sportschaden 1991;5:22-6.

9 Kinney PL, Nilsen DM, Lippmann M, et al. Biomarkers of lung inflammation in recreational joggers exposed to ozone. Am $\mathcal{F}$ Respir Crit Care Med 1996;154:1430-5

10 Greendale GA, Barrett-Connor E, Edlestein S, et al. Lifetime leisure exercise and osteoporosis. The Rancho Bernardo Study. Am f Epidemiol 1995;141:951-9.
11 Tabib A, Miras A, Taniere P, et al. Undetected cardiac lesions cause unexpected sudden cardiac death during occasional sport activity. A report of 80 cases. Eur Heart 7 1999;20:900-3.

12 Woods RL, Thomson WD. Effects of exercise on aspects of visual function. Ophthalmic Physiol Opt 1995;15:5-12.

13 Qureshi I. Does physical fitness effect intra-ocular pressure? fournal of the Pakistan Medical Association 1997;47:81-4

14 Aldoori WH, Giovannucci EL, Rimm EB, et al. Prospective study of physical exercise and the risk of diverticular disease in men. Gut 1995;36: 276-82.

\section{Encouraging stair walking}

A motivational poster placed at a choice point between escalator and stair use, in a city centre underground station, doubled stair use (fig 1). ${ }^{1}$ The study also showed that men and boys used the stairs more than women and girls both before and after the poster intervention, but there was no obvious explanation of this finding. ${ }^{2}$ Follow up interviews with 200 stair users or escalator users showed that motivational posters can change the behaviour of people who are not very active as not all those using the stairs were regularly active. The barriers to stair use were time, laziness, and effort, while the motivations for stair use were saving time and improving health. Women cited laziness as the key barrier to stair climbing and in comparison with men perceived stair climbing as requiring more effort. ${ }^{3}$

The study results led to the design and distribution of stair walking promotional posters throughout Scottish workplaces by the Health Education Board for Scotland. Within Glasgow a new promotional campaign was developed using life size cut out cartoon characters placed at the foot of escalators, as posters on platforms, and as advertising cards on trains (fig 2). These materials encouraged stair use and had straplines explaining the health benefits of small amounts of physical

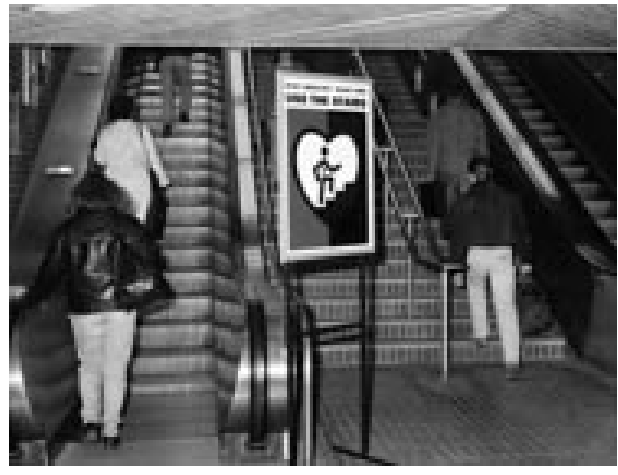

Figure 1 Motivational poster placed between stairs and escalators. activity. The campaign has run for two 12 -week periods in all Glasgow underground venues. Several other studies have shown the efficacy of motivational signs promoting stair use.

NANETTE MUTRIE

Centre for Exercise Science and Medicine, University of Glasgow

AVRIL BLAMEY

Health Promotion Department, Greater Glasgow Health Board, Scotland

1 Blamey A, Mutrie N, Aitchison T. Promoting active living: increasing stair walking by motivational stimulus cues. increasing stair walking

2 Mutrie N, Blamey A, Aitchison T. Why do fewer women choose the stairs? F Sports Sci 1996;14:16-17.

3 Mutrie N, Blamey A, Mitchell J. What stops people choosing the stairs? Proceedings of the American College of Sports Medicine Physical Activity Interventions Conference, Dallas. 1997.

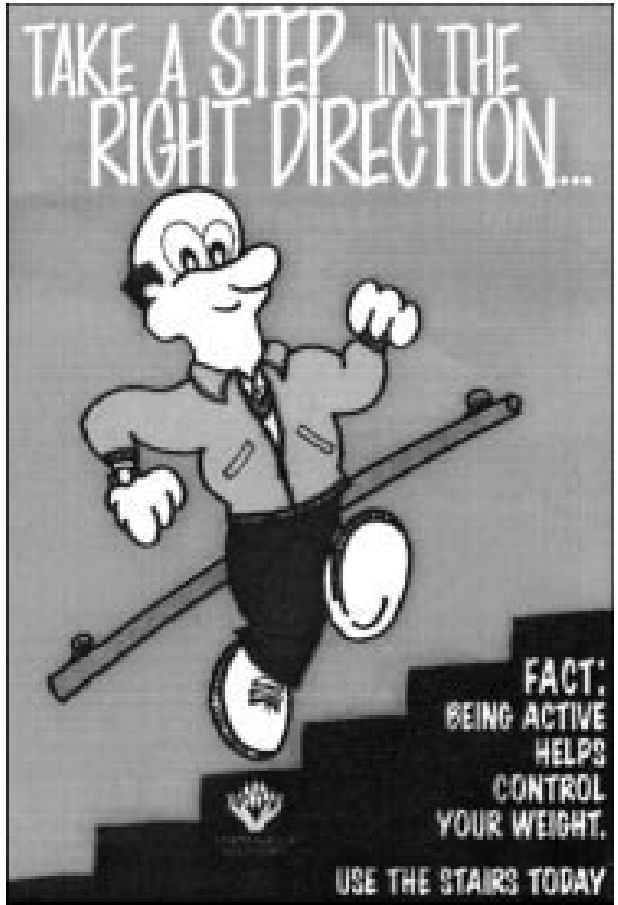

Figure 2 Promotional campaign. Reproduced with permission of the Greater Glasgow Health Board. 